\title{
WORLD OF CRYPTO CURRENCY: A SURVEY
}

\author{
Reetu Singh \\ Department of CSE \\ Galgotias University, Greater Noida, \\ Uttar Pradesh, India
}

\author{
Km Manisha Rai \\ Department of CSE \\ Galgotias University, Greater Noida, \\ Uttar Pradesh, India
}

\begin{abstract}
Crypto currency, an encoded, peer-to-peer network for encouraging digital barter, is a revolution created eight years back. Bitcoin, the first and most remarkable crypto currency, is making ready as a troublesome revolution to long standing and invariable budgetary installment structure that have been establish for a long time. While digital figure of money are not liable to substitute customary directive cash, they could replace the way Internet-associated international markets interface with one flipside, gathering high hindrances encompassing regularizing national capital standards and trade rates. Revolution launch at a fast rate, and the achievement of a given revolution is exclusively conducted by the market upon which it looks to progress. Cryptographic structure of money may alter computerized interchange showcases by making a free of charge streaming interchanging structure without expenses. AASWOT inspection of Bitcoin is betrayed, which lights up a part of the in progress occasions and growth that could impact even if Bitcoin build on to a move in monetary absolute models. A clearly distributed form of computerized money would authorize online segment to be sent exactly starting with one congregation then onto the next without exercising a economic foundation. Virtual Currencies and cryptographic money is another computerized expansion to the digital world and in addition worldwide budgetary framework that has not yet been completely regulated into the lawful structure of numerous countries over the globe. There are numerous lawful parts of Bitcoin and digital money all in all to consider.
\end{abstract}

\section{Keywords- Crypto Currency; Bitcoin; SWOT} Investigation

\section{INTRODUCTION}

The vast majority of us know about applying advanced monetary structure. As far back as IBM send out their 3651 controller and 3663 checkout workstation in 1973, the job of modern cash has matured, pushing the limitation of flexibility, accommodation, and safety. At of the finish of September 2017, Coin advertise top a digital money showcase tracker records more than 1,100 cryptographic forms of money that exchange more than 5,500 markets worldwide and with a total esteem drawing nearer USD 150bn; extra than the market funding of IBM and McDonald's. The most noticeable,
Bitcoin, represents simply under part of this. The majority of us know about applying computerized monetary standards. Trying to fulfill the interest of people searching for a computerized stage to execute safely, secretly, and outside of government impact, since 2008 the volume and use of digital money has detonated.

\section{CHARACTERISTICS OF CRYPTO CURRENCY}

Cryptographic money is automated or electronic cash that utilizes cryptography for safety . Digital money is hard to copy as a result of this safety highlight. A identifying highlight of cryptographic money, and apparently its most pleasant appeal, is its essential nature; it is not issued by any focal authority, rendering it hypothetically insensitive to government impedance or command.

The 3 main characteristics of crypto currency is given below:

Trustless

\section{Decentralized}

Immutable

As Bitcoin is the primary crypt currency money at any point made, It is the first to display the 3 key attribute we will cover later on.

\section{Trustless}

Bitcoin is trustless in light of the fact that it was structured such that no one needs to confide in any other person all together for the system to work. Each type of money before bitcoin required a focal specialist that you needed to trust so as to utilize it. In all cases, that focal authority turns into the focal weakness that prompts the demise of the currency.

Decentralized

Since "decentralization" is such a significant popular expression in the crypto network, it's essential to characterize it well. It can take on various implications.

Decentralized systems are Fault tolerance, Attack Resistance, Collision Resistance.

Immutable

Immutable", in its least complicated sense, signifies "can't be fixed. Unchanging nature with relevancy square chain and cryptographically money got to pursue three standards.

It ought to be profoundly unrealistic or hard to revise history. 


\section{International Journal of Engineering Applied Sciences and Technology, 2020 \\ Vol. 5, Issue 5, ISSN No. 2455-2143, Pages 265-269 \\ Published Online September 2020 in IJEAST (http://www.ijeast.com)}

- It should be inconceivable for anybody however the proprietor of a private key to move reserves.

- All exchanges are recorded on the square chain. (to ensure the over 2 standards)

\section{TYPES OF CRYPTO CURRENCY .}

\section{A. Bitcoin}

Bitcoin is a electronic currency and overall portion structure. It is the primary decentralized computerized cash, as the framework works without a national bank or single chairman. The system is shared and exchanges happen between customers specifically, without a mid person.

\section{B. Ethereum}

Ethereum is likewise named as Ether as this cryptographic money is produced on Ethereum stage. It is open stage with open source, square chain based figuring. It has a savvy scripting office. It takes a shot at the changed variant of Nakamoto's digital currency with exchange based installment framework.

\section{Litecoin}

Litecoin is treated as a main opponent for Bitcoin as of now and the principle reason for planning Litecoinwas to process littler esteem exchanges quick. Litecoin was established in October, 2011. As indicated by the originator of Litecoin, Charles Lee, Litecoin was considered as a silver against bitcoin which was tend as a gold.

\section{Swell}

Ripple was propelled in 2012 by an organization called Open Coin with its author, an innovation business visionary Chris Larsen. Swell is a money and also an installment framework like Bitcoin.

\section{E. MintChip}

Mintchip is really a making of government foundation like Royal Canadian Mint dissimilar to most different cryptographic forms of money. MintChip is a smartcard that holds digital esteem and can swapping it safely starting with one chip then onto the other chip. Like Bitcoin, MintChip does avoid individual ID but rather not at all love Bitcoin, it is validate by a physical money, the Canadian dollar.

\section{CHALLENGES AND ISSUES}

The type of cryptographic configuration of money is not free from some budgeting problems and safety concerns. I broke down a few investigations and cryptographic cash stages and furthermore watched a few digital currency pitching gatherings with end goal to inspecting difficulties and problem that are survive in such networked marvel. The principle problems and effects of cryptographic money can involve.

\section{A. Safety Dangers}

Hackers and malevolent clients can make as more as they demand from virtual cash on the off chance that they break the structure and know the technique for virtual money externalization. This will prompt the volume to make copy virtual cash or take virtual money by simply exchanging the records adjusts.

\section{B. Gold Cultivating Dangers}

Gold cultivating term is extremely prominent in China and creating nations. Gold ranchers are athlete who play in civilized amusements, for example, World of War craft with the end goal to increase gold, which is virtual money of the distraction, and after that move it for genuine cash.

\section{Variance In Virtual Money Esteem}

According to Guo and Chow ponder, it seen that when the notoriety of a virtual network drops, estimation of its virtual cash will be depreciated. For instance, customers who claim 1000 units of virtual money can buy from assortment of 100 things. In the event that the distributor of that virtual money drops, customers can just buy from 10 things with their 1000 units since lowering will be speculated in less merchandise and enterprises exceptionally in shut virtual networks.

\section{Illegal Tax Avoidance}

Money laundering is one dangerous that is probably going to rise with the use of $\mathrm{VC}$ particularly with phases that empower customers to trade virtual money with certain cash. In functional case occurred in Korea in 2008, the police arrest a gathering of 14 people for washing \$38 million got from moving networked money. The gathering changed over the estimate of $\$ 38$ million, which is created by gold cultivating, from Korea to a paper association in China as installment plan for buys.

\section{CRYPTOCURRENCY AND LAWS}

Other than worries and complications that are confronting present virtual cash structures, I inspected the authoritative issues that are probably going to smash digital money utilize. Additionally, a few claims and certifiable rules that are probably going to be activated with networked money production are engaged with our investigation.

\section{Status of Authority on Crypto currency around the globe}




\section{International Journal of Engineering Applied Sciences and Technology, 2020 \\ Vol. 5, Issue 5, ISSN No. 2455-2143, Pages 265-269 \\ Published Online September 2020 in IJEAST (http://www.ijeast.com)}

Trading virtual money with genuine cash is an interesting issue in E-business and E-trade enterprises. Exchanging cryptographic money for money is restricted and denied in a few nations where in different nations, it is either permitted or not controlled yet.

\section{A. United States (Friendly)}

The United State has been adopting a strategy to cultivate development and development of block chain and cryptographic money while shielding financial specialists from high dangers and extortion.

\section{B. Canada (Friendly)}

The Economical Consumer Agency of Canada (FCA) distributes online data with respect to advanced and cryptographic forms of money. The FCA clarifies parts of decentralization, distributed exchanges, computerized wallets, wallet safety, and the dangers of utilizing advanced cash. They additionally keep up that computerized monetary forms are not legitimate delicate, and that benefits produced using advanced monetary standards are liable to Canada's Income Tax Act. Products and enterprises trades for cryptographic money must be accounted for as pay for duty motive, and exchanges amongst digital currencies are viewed as ware exchanges, and should be accounted for.

\section{China (Hostile)}

China is infamous for a portion of the world's biggest bitcoin mines. In 2017, China restricted cryptographic money exchanging on Chinese trades and made ICO gathering pledges unlawful, bending market request, and causing a substantial in general downtrend in the digital currency markets.

\section{South Korea (Neutral)}

The digital currency market's record-breaking peak in Jan 2018 were immediately hushed, to some degree from fears that South Korea may boycott cryptographic money exchanging a way like China.

\section{Real world laws affecting virtual money}

With the pay assess division slapping charge sees on just about five lakh high total assets people executing in bitcoin, the issue of exhausting digital forms of money has accepted more significance and criticalness in India.

\section{A. Gift voucher laws}

Some virtual money suppliers offer virtual money on a prepaid premise. Customers and clients can buy prepaid cards to finance their documentation with virtual cash, for example, Facebook diversion card. This sort of CC is basically the same as plastic present vouchers since both are utilized for later recovery and utilize. Along these lines, gift voucher laws are destined to be connected on digital currency sold as a prepaid card.

\section{B. Betting/lottery laws}

Few administrators offer virtual money as a prize in virtual lottery. Few others enable clients to wager and play betting recreations utilizing networked money. These sorts of amusements and internet betting with virtual cash may trigger betting rules in a few nations. For instance in India, as per the Common Gaming Act, 1867 it could be contended that working a betting site in India is regarded unlawful under the terms of this demonstration, given its phrasingg, however this is a long way from understandable.

\section{Cash transmittal licensure laws}

Virtual money utilize grows and turns out to be most famous in various applications and diversions. This need administrators to connect with visitors enabling customers to reclaim or trade their electronic money for items given by those visitorss. For this situation, customers need to transmit their virtual cash to the visitors.

\section{CICRA Act}

There is few theory demonstrate that The Credit Information Companiess Regulation (CICRA) Act, which is s into law in India in 2005, is probably going to be connected on digital money because of its immense development.

Since digital money stages wind up normal place for some exercises, for example, putting away, transmitting, reclaiming, moving and trading the estimation of cryptographic money, CICRA Act prerequisites can be connected.

\section{E. Information protection and safety laws}

Few virtual money distibutors acquire data and knowledge about their customers. Phases that permit buying virtual cash with Mastercards must think about these laws as well while putting away the charge cards data. Such information must be kept and put away with high protection and security principles. Something else, the VC supplier may break information protection and safety laws. For instance, in India the Information Technology Act read with the Information Technology (Reasonable safety practices and systems and delicate individual information or data) Rules, 2011 obliges 


\section{International Journal of Engineering Applied Sciences and Technology, 2020 \\ Vol. 5, Issue 5, ISSN No. 2455-2143, Pages 265-269 \\ Published Online September 2020 in IJEAST (http://www.ijeast.com)}

everybody in charge of utilizing information to pursue strict principles. These standards incorporate the reality and the reason for which the data is being gathered, giving and distributing protection arrangement and guarding information secure.

\section{F. Kids insurance laws}

Since expansive extent of web based gamers are minors, kids security laws are probably going to be activated web based diversion sites that give VC. These laws are entirely ensure youngsters security. For instance, Article 16 of the Convention on the Rights of the Child (CRC) forces strict commitments to ensure youth under 13 years of age. The demonstration confines how and what individual data that sites and specialist organizations can gather from kids under 13. It needs the administrators to give a reasonable protection arrangements on their site that incorporate discloses on the best way to reach them, how the youngsters' information will be utilized and whether information will be accessible for outsiders. Besides, the articles likewise needs the administrators much of the time to get an assent from guardians before gathering or utilizing kids' information.

\section{G. Tax assessment}

Taxation law in virtual cash association is fluctuate from nation to nation. A few nations force imposes on livelihoods that are produced from virtual money exchanges and some others have recently thought about tax collection law. In India, if any such instrument is informed by RBI, any exchanging it will be liable to The Foreign Exchange Management (FEMA) Act, 1999. The Crypto like bitcoinsare considered a money resource in the event that they are acquired for venture. Any gain emerging on exchange of a bitcoin will be assessable as money gain. Notwithstanding, if the exchanges in bitcoins are significant and visit, it could be held that the citizen is exchanging bitcoins, and the pay would be assessable as association salary according to the Income Tax (IT) Act, 1961. The trouble of deciding clients' areas may compel tax collection usage. Following the VC trans-activities is additionally troublesome and this may restrict the usage of tax assessment.

\section{WHY DO CRYPTOCURRENCY SUCH AS BITCOIN HAVE VALUE}

One of the most concerning problem with advanced money is that bits are anything but tough to make and repeat on Personal Computers. For cash to work in an economy it must be to a great degree tough to imitate. Additionally, to have esteem cash must have few security against different expending of a alike coin - it needs to move amongest proprietors when spent. Imitating computerized cash is a lot less challenging than with physical ones. An answer to this problem is having a confided in a focal specialist that tracks swaps with the cash and furthermore ensures every swap. The biggest digital money, Bitcoin, took another course to cease this problem. (Dwyer, 2014) The business with Bitcoin happens entirely in shared arrangement of individuals where no foundation or focal authority is guaranteeing trades. A distributed system is an association between two Personal Computerss that can communicate or execute with one and other without interfacing with a different server Personal Computers. (Adapt, J. 2002) As said previously, Bitcoin simmilarly depends on open source programming. Open source implies that the programming code has atmost no copyright confinements, has been circulated carefully to anybody on the planet and any individual who so wants can alter the code. Open source is in this manner like shared systems as the improvement is finished by the members, for example, software engineers, and not a focal figure. (Dwyer, 2014) Using this open-source technique and shared systems, Bitcoin has possessed the size to utilize validation measures to take care of the proliferation problems. As referenced previously, all swapping with Bitcoin are recorded in a database called the square chain. Various sites keep duplicates of the square chain which they keep refreshed. Since Bitcoin has effectively countered the generation problem it can make esteem. Be that as it may, money should simmilar have a specific measure of interest to have esteem. (Dwyer, 2014) One explanation behind utilizing computerized cash is the manner by which lower the expense of money exchange is. Exchanging money carefully requires no physical cash to be exchanged and is additionally quick. It is additionally tough to keep individuals from bringing their Bitcoin wallets into another country and exchanging electronic currency for proximity money. A certain interest in this manner originates from the likelihood of staying away from money controls or gadministration impedance. The minor profit of such an exchange can be a lot higher than the minor expense. Another explanation behind the interest of advanced money is secrecy. (Dwyer, 2014) Another conceivable wellspring of interest for cryptographic cash is in this way individuals who wish to take an interest in online illegal businesses, utilizing the namelessness of Bitcoin. The Silk Road, an online mysterious commercial center, was one case of such bootleg trades. The Silk Road utilized Bitcoin as its fundamental trade money. The commercial center was utilized to move legislatively controlled substances and unlawful opiates where exchanges were holed up behind the namelessness of Bitcoin and dispatched anyplace on the planet. In a paper by Nicolas Christin, the income made by every person of the dealers was calculated to be about $\$ 1.2$ million per month. In a similar paper, Christin, utilizing a 29-day moving normal to figure the measurement, discovered that Silk Road exchanges related to about $4,5 \%$ to $9 \%$ of all Bitcoin trades. At the point when this commercial center was brought somewhere near the FBI, the cost of Bitcoin promptly decreased. (Christin, 2015) This 


\section{International Journal of Engineering Applied Sciences and Technology, 2020 \\ Vol. 5, Issue 5, ISSN No. 2455-2143, Pages 265-269 \\ Published Online September 2020 in IJEAST (http://www.ijeast.com)}

recommends the intrigue and interest for cryptographic cash originates from its secrecy and use in illicit exchanges. Despite the fact that Bitcoins are not inalienably unknown, proprietors can find a way to conceal their exchanges, particularly through worldwide Bitcoin trades, for example, Mt. Gox. The Mt. Gox. Trade, which was situated in Tokyo, was the greatest universal Bitcoin trade. Individuals everywhere throughout the world exchanged Bitcoins on the trade through Personal Computers. The trade was framework driven which implies that specific individuals would offer Bitcoins up for offer and the coins were exchanged through such market orders.

\section{CONCLUSION}

In this paper, we try to explain the things related to Cryptocurrency. We explain the characteristics of cryptocurrency then types of cryptocurrency, challenges, and issues of cryptocurrency and Laws and Acts related to cryptocurrency. We also try to explain why do cryptocurrency like bitcoin has so much value. Cryptographic money seems to have moved past the early appropriation phase that new advances involvement. Indeed, even engine automobile encountered this wonder. Bitcoin has aid to cut itself a strength advertise, which could assist advance cryptographic structure of money other into getting to be standard; or be its main driver falling flat. Cryptographic structure of money are still in their outset, and it is hard to check whether they will ever find real standard proximity in world markets.

\section{REFERENCES}

[1] Berentsen, Aleksander. "Monetary Policy Implications of Digital Money.'Kyklos (International Review of Social Sciences), 1998, 51(1), pp. 89-117; https://doi.org/10.1111/1467-6435.00039.

[2] Giudici Giancarlo, Milne Alistair, \& Vinogradov Dmitri 17 septmber 2019 Cryptocurrencies: market analysis and perspectives Journal of Industrial and Business Economics volume 47, pages1-18(2020).

[3] Berentsen, Aleksander and Schär, Fabian. Bitcoin, Blockchain und Kryptoassets: EineumfassendeEinführung. Books on Demand, Norderstedt, 2017.

[4] Furness, William H. The Island of Stone Money: Uap of the Carolines. Philadelphia: J. B. Lippincott, 1910. Kiyotaki, Nobuhiro and Wright, Randall."A SearchTheoretic Approach to Monetary Economics." American Economic Review, 1993, 83(1), pp. 63-77.

[5] Nakamoto, Satoshi. "Bitcoin: A Peer-to-Peer Electronic Cash System." 2008; https://bitcoin.org/bitcoin.pdf
[6] Bitcoin: A New Global Economy. (2015, August 4). Retrieved July 2016, from BitPay, Inc. Website: https://blog.bitpay.com/bitcoin-a-new-global-economy/

[7] Nosal, Ed and Rocheteau, Guillaume. Money, Payments, and Liquidity. Cambridge and London: The MIT Press, 2011; https://doi.org/10.7551/mitpress/9780262016285.001.000 1.

[8] Schär, Fabian and Langer, Dominik. "Smart Contracts einemissverstandeneTechnologiemithohemPotenzial."Syn pulse Magazin, 2017, 3(17), pp. 38-41

[9] Agence France-Presse. (2015, July 8). Switzerland begins postal delivery by drone. Retrievedfrom theguardian.com: http://www.theguardian.com/technology/2015/jul/08/swis s- postbegins-testing-postal-delivery-by-unmanned-drone

[10] AUVSI. (2014). Connecting the Unmanned Systems Community Across the Globe. Retrieved from auvsi.org: http://www.infoag.org/abstract_papers/papers/paper 236. pdf

[11] AV. (2015). Annual Reports. Retrieved from AVinc.com: http://investor.avinc.com/annuals.cfm

[12] Canis, B. (2015). Unmanned Aircraft Systems (UAS): Commercial Outlook for a New Industry . Washington: Congressional Research Office

[13] Carvalho, S. (2015, February 24). Firms see drone sales in Gulf surging after U.S. eases export policy. Retrieved fromReuters.com:http://www.reuters.com/article/2015/02/ 24/mideast usa-drones-idUSL5N0VY2GU20150224

[14] Brennan, C., \&Lunn, W. (2016, August 3). Blockchain. Retrieved from Finextra: https://www.finextra.com/finextradownloads/newsdocs/document-1063851711.pdf

[15] Clancy, T. (2016, January 20). Ecommerce at Large Coming Around to the Idea of Bitcoin. Retrieved from Cryptocoins News: https://www.cryptocoinsnews.com/ecommerce-atlargecoming-around-to-the-idea-of-bitcoin/

[16] CNBC. (2015). The top Hispanic entrepreneurs in America. Retrieved from CNBC: http://www.cnbc.com/2015/05/01/the- top-hispanicentrepreneurs-in-america.html?slide $=8$

[17] DeVries Peter D. ; September 2016 An Analysis of Cryptocurrency, Bitcoin, and the Future International Journal of Business Management and Commerce Vol. 1 No. 2.

[18] Chauhan Varun ; Arora Ginni Published in: 2019 2nd International Conference on Power Energy, Environment and Intelligent Control (PEEIC)A review paper on cryptocurrency \& portfolio management DOI: $\underline{\text { 10.1109/PEEIC47157.2019.8976592 }}$ 